\title{
Perspective/Discussion
}

\section{Importance of Doping, Dopant Distribution, and Defects on Electronic Band Structure Alteration of Metal Oxide Nanoparticles: Implications for Reactive Oxygen Species}

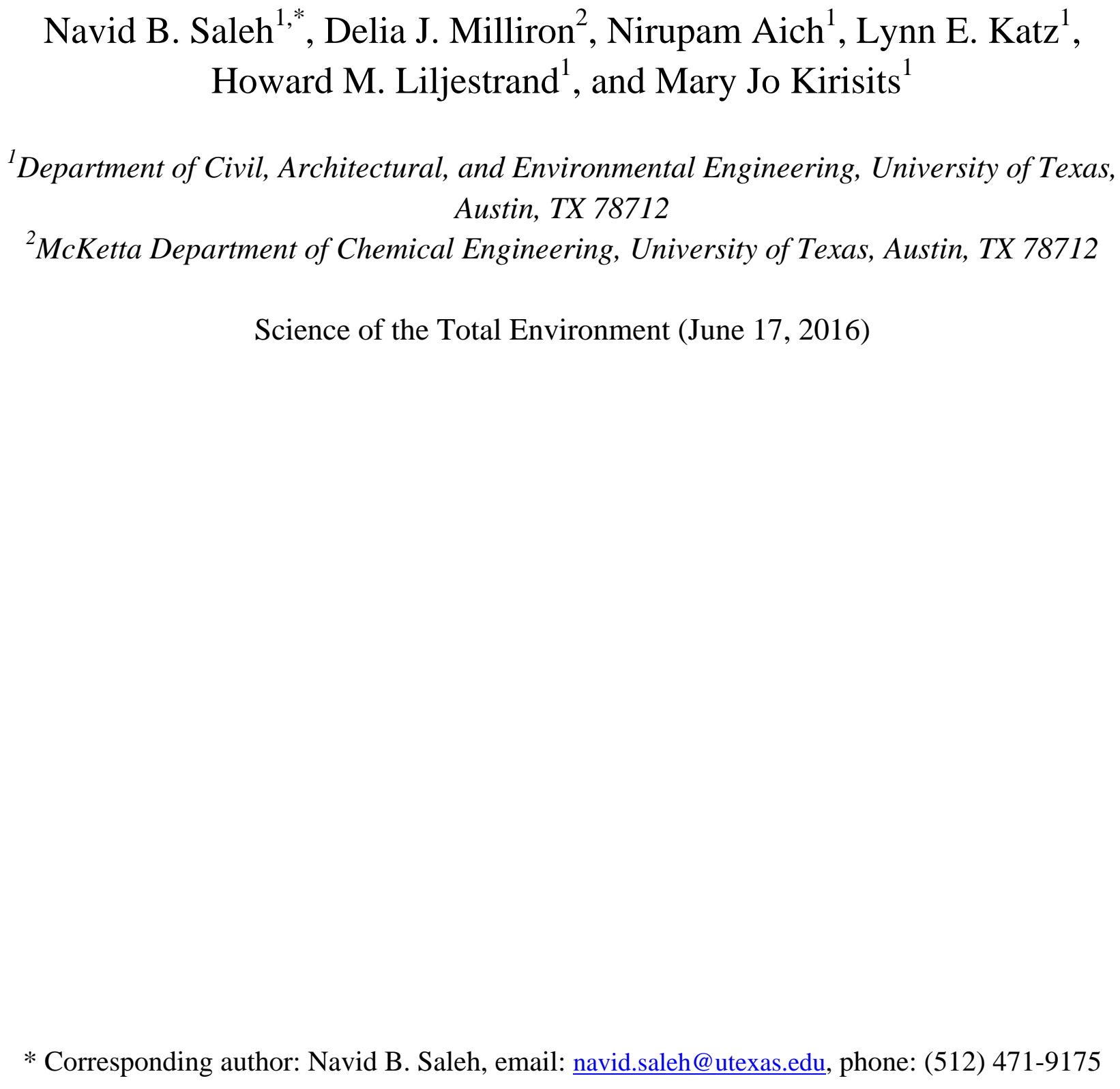

${ }^{1}$ Department of Civil, Architectural, and Environmental Engineering, University of Texas, Austin, TX 78712

${ }^{2}$ McKetta Department of Chemical Engineering, University of Texas, Austin, TX 78712

Science of the Total Environment (June 17, 2016) 9

2

3

(1)
9 30 31 . 


\section{Abstract}

Nano-scale metal oxide particles are considered to have the potency to generate reactive oxygen species (ROS), one of the key mechanisms underlying nanotoxicity. However, the nanotoxicology literature demonstrates a lack of consensus on the dominant toxicity mechanism(s) for a particular metal oxide nanoparticle (MONP). Moreover, recent literature has studied the correlation between band structure of pristine MONPs to their ability to introduce reactive species and thus has downplayed the ROS-mediated toxicological relevance of a number of such materials. On the other hand, material science can control the band structure of these materials to engineer their electronic and optical properties and thereby is constantly modulating the pristine electronic structure. Since band structure is the fundamental material property that controls ROS-producing ability, band tuning via introduction of dopants and defects needs careful consideration in toxicity assessments. This commentary critically evaluates the existing material science and nanotoxicity literature and identifies the gap in our understanding of the role of important crystal structure features (i.e., dopants and defects) on MONPs' electronic structure alteration as well as their ROS-generation capability. Furthermore, this commentary provides suggestions on characterization techniques to evaluate dopants and defects on the crystal structure and identifies research needs for advanced theoretical predictions of their electronic band structures and ROS-generation abilities. Correlation of electronic band structure and ROS will not only aid in better mechanistic assessment of nanotoxicity but will be impactful in designing and developing ROS-based applications ranging from water disinfection to next-generation antibiotics and even cancer therapeutics.

Keywords: Band gap, nano-defects, nanotoxicity, nano-imperfections. 


\section{Introduction}

60 Metal oxide nanoparticles (MONPs) are one of the most prepared and used engineered nanomaterials with applications in electronics, optical devices, medical processes and devices, catalysis, alternative energy production, and environmental remediation and as antimicrobial sprays and coatings (Murphy et al., 2005). Manufacturing processes, and end-of-life disposal events for these applications might serve as exposure pathways to humans and the natural environment and thus raise concerns for eco- and nano-toxicity (Klaine et al., 2008; Nel et al., 2006; Saleh et al., 2015). The key mechanisms for toxicity from MONPs include dissolved ions, alteration of redox potential and subsequent catalytic reaction, and reactive oxygen species (ROS) and their interaction with biological entities (Aich et al., 2014; Ju-Nam and Lead, 2008; Saleh et al., 2015; Sarkar et al., 2014; von Moos and Slaveykova, 2014).

ROS, e.g., singlet oxygen, hydrogen peroxides, and superoxides, are known to cause toxicological stress to cells via alteration of redox-mediated cellular processes and damage to cellmembranes and other cellular components (Nel et al., 2006; Saleh et al., 2014; von Moos and Slaveykova, 2014). Some of the key interactions include lipid peroxidation leading to disruption of the cell-membrane (Nel et al., 2006), protein oxidation resulting in imbalance of enzymatic activities (Kumar et al., 2011), nucleic acid oxidation followed by genetic mutation and developmental toxicity ( $\mathrm{Nel}$ et al., 2006). The free radicals can participate in membrane protein remodeling, both in prokaryotic and eukaryotic cells, to alter permeability through the membranes (Pacurari et al., 2011; Zhang et al., 2010). The radicals also can reduce the production of natural antioxidants such as glutathione, superoxide dismutase, and catalase (von Moos and Slaveykova, 2014).

Generation of these reactive species occurs by electron transfer from the MONP surfaces, initiated by the energetic positioning of the electronic bands (Figure 1) as indicated by recent 
literature (Burello and Worth, 2011; Gajewicz et al., 2015; Kaweeteerawat et al., 2015; Zhang et al., 2012). Fundamental electronic structure and distribution of metals control the electronic band positioning. However, imperfections at the nano-scale (Janotti and Van de Walle, 2007; Laks et al., 1991) and introduction of secondary metals as dopants (Buonsanti and Milliron, 2013), further modulate the band structure (Figure 2). Such modulation can either be incidental (during synthesis) or engineered (to extract desired electronic properties) and both can contribute to an altered ability to generate ROS. Furthermore, the confounding conclusions about the key mechanisms of MONP nanotoxicity (Djurišić et al., 2015; von Moos and Slaveykova, 2014) should consider crystal defects and dopants due to, their ability to generate a wide range of ROS. Identifying the thermodynamic favorability of dopant or defect mediated ROS-generation by MONPs will eventually enabled screening of MONPs for ROS-generation kinetics. However, the effects of unintentional nano-scale imperfections or intentional defects and dopant distribution of MONPs on their ROS-generation ability have not been systemically evaluated in most nanotoxicity studies. This commentary focuses on band structure alteration of doped and defected MONPs and discusses the toxicological consequences and potential future strategies to better characterize lattice defects and dopants.

\section{Mechanisms of metal oxide nanoparticle toxicity}

Nanotoxicity of a large set of metal oxide (e.g., $\mathrm{TiO}_{2}, \mathrm{CuO}, \mathrm{ZnO}$, cerium oxide $\left(\mathrm{CeO}_{2}\right)$, iron oxide $\left(\mathrm{Fe}_{2} \mathrm{O}_{3}\right)$, manganese oxide $\left.\left(\mathrm{Mn}_{2} \mathrm{O}_{3}\right)\right)$ particles has been assessed, and quantitative structure activity relationship (QSAR) models on ROS and band gap (Kaweeteerawat et al., 2015; Zhang et al., 2012), hydration energies (Kaweeteerawat et al., 2015), or enthalpy of formations (Gajewicz et al., 2015) have been proposed. Despite such promising advances, conflicting reports regarding the dominant mechanism of toxicity continues to surface for most MONPs, while consensus 
exists for the ROS-mediated toxicity due to nano-scale $\mathrm{TiO}_{2}$ (Bar-Ilan et al., 2012; Djurišić et al.,

108 2015). For example, some reports on $\mathrm{ROS}$ control of $\mathrm{ZnO}$ (a photocatalyst) toxicity 109 (Kaweeteerawat et al., 2015; Kumar et al., 2011; Li et al., 2014; Sharma et al., 2012) conflict with 110 the dominant mechanisms of dissolution and particle-cell interaction that are reported elsewhere 111 (Buerki-Thurnherr et al., 2013; Chusuei et al., 2013; Song et al., 2010; Zhang et al., 2012), where 112 the latter ones (Buerki-Thurnherr et al., 2013; Chusuei et al., 2013; Song et al., 2010; Zhang et al., 113 2012) mention that particle-induced ROS was not playing a significant role in ZnO nanotoxicity. 114 Other MONPs, including $\mathrm{CuO}, \mathrm{CeO}_{2}$, and $\mathrm{Mn}_{2} \mathrm{O}_{3}$, showed similar contradiction (Table 1) in 115 dominant toxicity mechanisms (Djurišić et al., 2015). The sources and synthesis techniques of the 116 MONPs for these studies varied widely (Table 1), with no reported assessment of MONP band structure. Differences in synthesis techniques (for the same MONP) introduce differences in crystal defects and dopants. For example, nitrogen-doped $\mathrm{TiO}_{2}$ contained a higher dopant concentration in the crystal structure and consequently higher visible light activity when urea was used as the nitrogen source as compared to the usage of molecular nitrogen or inorganic nitrogenous compounds (Rehman et al., 2009). Use of nitrous oxide $\left(\mathrm{N}_{2} \mathrm{O}\right)$, on the other hand, can cause a higher degree of transformation from anatase to rutile structures (Guo et al., 2007). Moreover, the presence or absence of post-synthesis annealing also is known to contribute to the extent and types of defects present in $\mathrm{ZnO}$ nanorods, modulating their photocatalytic activities (Das et al., 2014). It is thus probable that these MONPs, synthesized via a multitude of techniques, ranged widely in band structure as a result of defects and doping; consequently, differences in band structure might have resulted in variations in their manifested toxicity (Djurišić et al., 2015). Other bio-related differences (e.g., media choice, bacterial strains, assay type) might also contribute to the lack of clarity in identifying the dominant mechanism of 
131 be ignored. Systematic characterization of defects and dopants in MONPs is critical to assess the

132 ability of these materials to generate ROS; then, inconsistencies among various studies regarding the role of ROS in the toxicity of a particular MONP can be resolved.

\section{Metal oxide nanoparticle band structure and ROS}

Band gap engineering and tuning the energetic levels at band edges are at the forefront of materials science, motivated by energy conversion and other electronic applications (Aich et al., 2014; Buonsanti and Milliron, 2013; Chen et al., 2004; Norris et al., 2008; Schimpf et al., 2012). The band gap energy $\left(E_{g}\right)$ of a material is determined by the positions of the valence band $\left(E_{v}\right)$ and conduction band $\left(E_{c}\right)$ edges (Figure 1). Energetic activation of metal oxide and other semiconductor nanomaterials, for example by light irradiation, enables excitation of electrons from $E_{v}$ to $E_{c}$; this results in the presence of excess of electrons in the conduction band and empty states or presence of electropositive 'holes' in the valence band (Figure 1)(Brunet et al., 2009).

Conduction band electrons at $E_{c}$ can act as strong reducers to react with oxygen molecules to produce the superoxide anion $\left(\mathrm{O}_{2}{ }^{-}\right)$, which can then act as a precursor for production of hydroxyl radicals $\left({ }^{\circ} \mathrm{OH}\right)$ and singlet oxygen $\left({ }^{1} \mathrm{O}_{2}\right)$. On the contrary, the holes (with their high oxidizing ability) can react with water or hydroxyl ions to produce hydroxyl radicals ( $\mathrm{OH}$ ) (Figure 1) (Burello and Worth, 2011). These ROS can then interact with biological entities, resulting in toxicity. To understand the ROS generation and relevant toxicity of these MONPs, the redox potentials of these different ROS have been correlated with different MONP electronic structures.

151 It has been shown that metal oxides with $E_{c}$ positioning within the cellular redox potential (CRP; 4.12 to $-4.84 \mathrm{eV}$ ) allows for ROS generation to occur in aqueous medium (Burello and Worth, 
positioning of their $E_{c}$ with the CRP was correlated with observed toxicological endpoints

155 (Kaweeteerawat et al., 2015; Li et al., 2012; Zhang et al., 2012).

156

157

158

159

160

161

162

163

164

165

166

167

168

169

170

171

172

173

174

175

176

177

The hypothesis that $E_{c}$ positioning of the pristine MONP with respect to the CRP will control MONP's ROS-generation abilities might hold true from an electrochemical perspective, if defect and dopant-free MONPs can be synthesized at the nano-scale. However, to synthesize (by grinding, thermal, colloidal, microwave, annealing techniques) of a rather perfect, i.e., defect-free, metallic nano-structure is not trivial and is rather uncommon (Janotti and Van de Walle, 2007; McCluskey and Jokela, 2009; Merz et al., 2011). Inherently defective nano-crystals are rather common to find in a synthesized MONP batch, where the defect distribution is also likely to vary between the batches. On the contrary, deliberate introduction of defects, as in doping metal oxides to obtain n-type and p-type structures or to tune the band gap for light absorption, is common in band gap engineering (Buonsanti and Milliron, 2013; Lounis et al., 2014b; Norris et al., 2008). Defects and dopants are known to alter the band structure (Janotti and Van de Walle, 2006; Lounis et al., 2014b; Norris et al., 2008), leading to deviations in $E_{c}$ positioning as compared to the pristine MONP band structure. Band bending and $E_{c}$ band edge shifts should be carefully measured and reported because such changes might give some MONPs the capability to produce ROS, thereby becoming eco- and nano-toxicologically relevant. For instance, indium oxide $\left(\mathrm{In}_{2} \mathrm{O}_{3}\right)$ and $\mathrm{ZnO}$ (Zhang et al., 2012), where the $E_{c}$ positioning in their pristine states does not fall within the CRP range, will undergo $E_{c}$ band shift upon introduction of dopants. Examples of such doped materials are Sn-doped $\mathrm{In}_{2} \mathrm{O}_{3}$ (Lounis et al., 2014a; Schimpf et al., 2014b), Mndoped ZnO (Bhat and Deepak, 2005), Ce-doped ZnO (Faisal et al., 2013). Comprehensive literature reviews discuss the effects of synthesis techniques or doping strategies on alteration of crystal structure, electronic properties, and catalytic response of MONPs (Buonsanti and Milliron, 2013; Djurisic et al., 2014; Kumar and Rao, 2015; Pan et al., 2013; Zhang and Lin, 2012). A 
careful evaluation of the importance of nano-defects and dopants in band gap alteration is thus essential.

\section{Role of doping, dopant distribution, and defects on band structure}

Doping of metal oxides is commonly pursued to attain improved electronic, optical, and catalytic performance (Chen et al., 2011; Garcia et al., 2011). The major mechanism behind such property tuning is to achieve control over doping (Figure 2) that alters electron transfer characteristics via changes in crystalline structure of the pristine MONP (Buonsanti and Milliron, 2013; Lounis et al., 2014a). Such changes lead to band gap narrowing or expansion, resulting in shifted $E_{c}$ positioning. For example, $\mathrm{TiO}_{2}$ is a commonly used photocatalyst that shows a reduction in band gap when doped with non-metals (e.g., N, C, S), transition metals (e.g., Fe, Cu, Ni, Cr, Pt), or noble metals (e.g., Pt, Au, Ag, Ru) (Pelaez et al., 2012). While undoped $\mathrm{TiO}_{2}$ is only photoactive in the UV range, doping-induced band gap narrowing enables it to become photocatalytic and to generate ROS under visible irradiation. This becomes possible due to changes in lattice parameters or dopants acting as electron traps preventing charge recombination, or due to an intermediate energy level introduced between the conduction and valence bands. Similarly, doping-induced band bending also is observed in Mn-doped ZnO (Bhat and Deepak, 2005) or Sndoped $\mathrm{In}_{2} \mathrm{O}_{3}$ (Lounis et al., 2014a), thus, increasing the ROS-generation ability as compared to their undoped counterparts. In many cases, such doping-induced conduction band edge shifts occur due to disruption of the lattice structure of the parent metal oxides by the dopants (e.g., Sn in case of Sn-doped $\operatorname{In}_{2} \mathrm{O}_{3}$ ). This results in an irreversible perturbation of the electronic structure and hence changes electr.on densities in the conduction band (Schimpf et al., 2014a). However, all these changes are dependent on the extent of doping and on dopant distribution (Bhat and Deepak, 2005; Lounis et al., 2014a; Lounis et al., 2014b; Schimpf et al., 2014a). 

imperfections in crystalline NPs, which then results in band structure alteration. Size and shapespecific MONPs are generally obtained via vapor deposition (Polarz et al., 2005; Xing et al., 2003), aqueous solution based growth (Tam et al., 2006), electrodeposition (Sauer et al., 2002), or via top-down approach such as milling of bulk metallic particles (Fecht, 1995). The bottom-up processes involve nucleation of dissolved ions in the presence of a substrate (or seed), that proceeds toward 'ripened' crystal structures (Leach et al., 2007). Depending on the substrate or precursor, temperature, gas pressure, post-synthesis annealing, and other such synthesis parameters, the crystal lattice ordering can vary significantly and the resulting strain leads to formation of defects (Devan et al., 2012; Schmidt-Mende and MacManus-Driscoll, 2007; Wang et al., 2008). In the case of metal oxides, variations in oxygen pressure, i.e., the ratio of precursor to oxygen during nucleation and growth stages, can control the extent of oxygen vacancies in the crystal structures (Liu et al., 2004). These imperfections lead to loss or gain of electrons from the conduction band, thereby, altering the electronic properties (Asthana et al., 2011; Ischenko et al., 2005; Janotti and Van de Walle, 2006). For example, wet chemical synthesis can lead to a reduction in the band gap of $\mathrm{ZnO}$ (e.g., $E_{g}$ of $-2.9 \mathrm{eV}$ for wet-synthesized vs. $-3.22 \mathrm{eV}$ for annealed) because of the surface defects present (Asthana et al., 2011). Similarly, biogenic or modified hydrothermal annealing of $\mathrm{CeO}_{2}$ nanostructures can lead to increases in $\mathrm{Ce}^{3+}$ and oxygen vacancies, resulting in band gap narrowing and photocatalysis via visible irradiation (Ansari et al., 2014; Lawrence et al., 2011). Top-down approaches, on the other hand, involve high energy input via mechanical attrition and non-uniform stress on the ground particles, which result in atomic shifts or dislocations from lattice or surfaces (Fecht, 1995; Leach et al., 2007)

224 leading to alterations in electronic properties. For instance, synthesis of $\mathrm{ZnO}$ via grinding (with 225 different capping agents) has shown to control oxygenated defect sites, thereby modulating their 
band gap (Jitti-a-Porn et al., 2011). Further, $\mathrm{TiO}_{2}$ band gap reduction through intentional defect engineering of pre-synthesized nanostructures has been achieved using electron-beam-assisted synthesis techniques (Khan et al., 2014a). Chemically bound surfactant or polymeric surface coatings or capping agents can reduce defects or imperfections on nanocrystal surfaces (Lakshmi Prasanna and Vijayaraghavan, 2015). The nature of bond formation on defect alteration need to be studied systematically to assess the role of coatings on electronic structure alteration.

\section{Nanotoxicological implications}

A few MONPs are known to produce ROS, driven by the inherent positioning of their $E_{c}$ band lying within the range of the CRP; these include $\mathrm{TiO}_{2}$, nickel oxide $\left(\mathrm{Ni}_{2} \mathrm{O}_{3}\right)$, cobalt oxides $(\mathrm{CoO}$ and $\left.\mathrm{Co}_{3} \mathrm{O}_{4}\right)$, chromium oxide $\left(\mathrm{Cr}_{2} \mathrm{O}_{3}\right)$, and $\mathrm{Mn}_{2} \mathrm{O}_{3}$ with $E_{c}$ positions at $-4.16,-4.31,-4.42,-4.59$, 4.44, and $-4.65 \mathrm{eV}$, respectively. The $E_{c}$ position for other important MONPs are beyond the CRP range, namely $\mathrm{In}_{2} \mathrm{O}_{3}, \mathrm{ZnO}$, and $\mathrm{CuO}$, and are not considered as critical MONPs from an environmental health and safety (EHS) perspective because of their assumed lack of ROS generation (Zhang et al., 2012). However, doping and defects will alter their band structure, thereby potentially allowing the $E_{c}$ level to fall within the CRP.

$\mathrm{In}_{2} \mathrm{O}_{3}$ doped with $\mathrm{Sn}$ could be one such case where the MONPs might become ROS-active upon doping. The $E_{c}$ positioning of $\mathrm{In}_{2} \mathrm{O}_{3}$ as independent metal oxide is outside the CRP range, and thus is considered as less toxic MONPs (Lison et al., 2009; Zhang et al., 2012). However, upon doping with $\mathrm{Sn}$, the conduction band of $\operatorname{In}_{2} \mathrm{O}_{3}$ bends as a function of the dopant distribution and concentration (Gilstrap, 2009; Lounis et al., 2014a). Recent reports suggest that extracellular and intracellular ROS production will occur from $\mathrm{Sn}$-doped $\operatorname{In}_{2} \mathrm{O}_{3}$, which has resulted in oxidative stress in zebra fish embryos (Brun et al., 2014; Lison et al., 2009). Similarly, while ZnO photocatalysts showed little antibacterial activity ( $\mathrm{E}_{\mathrm{c}}$ outside of the CRP), Fe- $(2.1 \%)$ and Mn- 
$(0.8 \%)$ doped $\mathrm{ZnO}$ resulted in elevated ROS generation and caused increased cytotoxicity (Yin

251

252

and Casey, 2014), likely via band gap modulation and $\mathrm{E}_{\mathrm{c}}$ repositioning within CRP (Figure 1) (Bharati et al., 2012; Hoque et al., 2014). Moreover, distribution, types, and concentrations of native point defects (e.g., oxygen vacancies) in nano-scale $\mathrm{ZnO}$ (Guo et al., 2011; Wang et al., 2012a; Zhang et al., 2014) also have shown to contribute to band gap alterations. A simple sonication-based technique has been used to induce defects in $\mathrm{ZnO}$ to enhance photoelectrochemical water splitting by band gap reductions (Wang et al., 2013). Similarly, $\mathrm{CeO}_{2}$, which is located far outside of the CRP- $E_{c}$ range and identified as a non-ROS generator (Zhang et al., 2012), has been shown to undergo band gap reduction and conduction-band modulation to achieve enhanced visible light activity and ROS production (Ansari et al., 2014; Khan et al., 2014b; Lawrence et al., 2011). Defect-mediated toxicological responses have been observed for Ag nanoparticles, which could not be completely explained by a dissolution-based mechanism (George et al., 2012). Since unintentional crystal defects and intentional band gap engineering controls the band structure of these materials, it is important to develop strategies for systematically assessing the role of doping and defects on the ability of this wide material class to generate ROS.

This commentary highlights that band structure alteration will result from dopants and defects in the nano-structure. The distribution and position of the dopants and defects will influence the electronic band properties. The nanotoxicology community assesses nanomaterial safety using materials synthesized with a wide variety of techniques. Defect incorporation and foreign atom introduction are highly probable in the MONP samples studied for safety assessment. Moreover, band gap engineering is precisely involved in modulation of band structure to attain the desired electronic properties for their applications. Further, band-engineered MONPs released from electronic or medical processes/devices might undergo transformation via 
274 dissolution, reaction, or photo-activation; which will alter the crystal structure of the particle

275 surface and add to the defects and dopant distribution complexity. Use of standard ROS assays

276 can be employed to differentiate the ROS-generation ability of MONPs with variable band-

277 structures originating from controlled defect-engineering and doping. However, since ROS

278 assays are average and overall measures, the sample of MONP with no control over crystal

279 defects and dopants could produce inconsistent conclusion on ROS generation potency,

280 depending on the degree of heterogeneity of these properties within the samples tested. Thus

281 synthesizing MONPs with a high degree of control over these crystal lattice attributes (i.e.,

282 defects and dopants) is essential to systematically assess ROS-mediated MONP toxicity.

283 Collaboration between the nanotoxicology and material science communities is thus necessary.

\section{Mechanistic strategies for atomistic MONP characterization}

What strategies can nanotoxicologists and material scientists undertake to expedite the safety assessment of ROS-active MONPs? To-date, the material science field has not developed a predictive tool that can accurately capture the band structure of a nanomaterial based on its pristine composition. Recently, notable efforts have been made to achieve theoretical predictability on band structure alteration by dopants and defects (Anderson and Chris, 2009; Andriotis and Menon, 2015); however, continued and systematic research is necessary to evaluate the role of dopant atoms' positioning (surface dopants vs. distributed) (Goings et al., 2014) in band structure modulation as well as its relationship to the ROS-generation-ability of MONPs. Such theoretical development can simplify the job of the nanotoxicology community to narrow down the important MONPs from the large set of ROS-active materials. Such predictability can be complemented with careful synthesis of MONPs possessing precise defects and dopant content 
such efforts, possibly preparing such MONP standards with controlled dopants and defects; such

299 materials could then be utilized to systematically assess their ROS-mediated nanotoxicity.

300 Furthermore, rigorous and detailed characterizations of dopants and/or defects also are critical.

301 Such characterization can be performed with X-ray diffraction (Wang et al., 2006), nano beam

302

303

304

305 diffraction with high-angle annular dark field scanning transmission electron microscopy (HAADF-STEM) (Ward et al., 2014), slow positron beam spectroscopy (Xue et al., 2013), photoluminescent (PL) emission (Sekiguchi et al., 2000; Zhang et al., 2014), X-ray absorption spectroscopy (XAS) (Brown and Parks, 2001; Rossi et al., 2014; Waychunas and Zhang, 2008), X-ray standing wave measurements (Zhang et al., 2004), and X-ray spectromicroscopy (STXM) (Chen et al., 2014; Myneni et al., 1999; Warwick et al., 1998). Not only material scientists but also nanotxicologists can add these characterization tools to the routine assessment sequence, depending on the ROS-generation ability of the MONPs (predicted or characterized by the material scientists). Nanotoxicologists on the other hand can continue to develop and utilize the power of high throughput assays to scan across a large material set to identify highly ROSproducing MONPs. Such initial screening techniques can then be utilized to develop standard materials (with controlled dopants and defects) of the most ROS-active MONPs. Systematic assessment of the role of dopants and defects are necessary to resolve mechanistic controversies on ROS-mediated MONP toxicity.

Acknowledgements. This work was funded by the National Science Foundation (CBET 1511826). The authors thank Mr. Jaime Plazas-Tutle and Mr. Evan Runnerstrom, Ph.D. students from Drs. Saleh's and Milliron's group, for their support with the illustrations.

\section{References}


Aich N, Plazas-Tuttle J, Lead J, Saleh N. A Critical Review of Nanohybrids: Synthesis, Applications, and Environmental Implications. Environmental Chemistry 2014; 11: 609-623.

Anderson J, Chris GVdW. Fundamentals of zinc oxide as a semiconductor. Reports on Progress in Physics 2009; 72: 126501.

Andriotis AN, Menon M. Band gap engineering via doping: A predictive approach. Journal of Applied Physics 2015; 117: 125708.

Ansari SA, Khan MM, Ansari MO, Kalathil S, Lee J, Cho MH. Band gap engineering of $\mathrm{CeO}_{2}$ nanostructure using an electrochemically active biofilm for visible light applications. RSC Advances 2014; 4: 16782-16791.

Asthana A, Momeni K, Prasad A, Yap YK, Yassar RS. On the correlation of crystal defects and band gap properties of ZnO nanobelts. Applied Physics A 2011; 105: 909-914.

Bar-Ilan O, Louis KM, Yang SP, Pedersen JA, Hamers RJ, Peterson RE, et al. Titanium dioxide nanoparticles produce phototoxicity in the developing zebrafish. Nanotoxicology 2012; 6: 670-679.

Bharati $P$, Aslam M, Bahadur D. Effect of Fe doping concentration on optical and magnetic properties of ZnO nanorods. Nanotechnology 2012; 23: 115601.

Bhat SV, Deepak F. Tuning the bandgap of $\mathrm{ZnO}$ by substitution with $\mathrm{Mn}^{2+}, \mathrm{Co}^{2+}$ and $\mathrm{Ni}^{2+}$. Solid State Communications 2005; 135: 345-347.

Brown GE, Parks GA. Sorption of Trace Elements on Mineral Surfaces: Modern Perspectives from Spectroscopic Studies, and Comments on Sorption in the Marine Environment. International Geology Review 2001; 43: 963-1073.

Brun NR, Christen V, Furrer G, Fent K. Indium and indium tin oxide induce endoplasmic reticulum stress and oxidative stress in Zebrafish (Danio rerio). Environmental Science \& Technology 2014; 48: 11679-11687.

Brunet L, Lyon DY, Hotze EM, Alvarez PJJ, Wiesner MR. Comparative Photoactivity and Antibacterial Properties of C60 Fullerenes and Titanium Dioxide Nanoparticles. Environmental Science \& Technology 2009; 43: 4355-4360.

Buerki-Thurnherr T, Xiao L, Diener L, Arslan O, Hirsch C, Maeder-Althaus X, et al. In vitro mechanistic study towards a better understanding of ZnO nanoparticle toxicity. Nanotoxicology 2013; 7: 402416.

Buonsanti R, Milliron DJ. Chemistry of doped colloidal nanocrystals. Chemistry of Materials 2013; 25: 1305-1317.

Burello E, Worth AP. A theoretical framework for predicting the oxidative stress potential of oxide nanoparticles. Nanotoxicology 2011; 5: 228-235.

Chairuangkitti P, Lawanprasert S, Roytrakul S, Aueviriyavit S, Phummiratch D, Kulthong K, et al. Silver nanoparticles induce toxicity in A549 cells via ROS-dependent and ROS-independent pathways. Toxicology in Vitro 2013; 27: 330-338.

Chambers BA, Afrooz ARMN, Bae S, Aich N, Katz L, Saleh NB, et al. Effects of chloride and ionic strength on physical morphology, dissolution, and bacterial toxicity of silver nanoparticles. Environmental Science \& Technology 2014; 48: 761-769.

Chen S-Y, Chen R-J, Lee W, Dong C-L, Gloter A. Spectromicroscopic evidence of interstitial and substitutional dopants in association with oxygen vacancies in Sm-doped ceria nanoparticles. Physical Chemistry Chemical Physics 2014; 16: 3274-3281.

Chen W, Zhang JZ, Joly AG. Optical properties and potential applications of doped semiconductor nanoparticles. Journal of nanoscience and nanotechnology 2004; 4: 919-947.

Chen X, Liu L, Yu PY, Mao SS. Increasing solar absorption for photocatalysis with black hydrogenated titanium dioxide nanocrystals. Science 2011; 331: 746-750.

Chusuei CC, Wu C-H, Mallavarapu S, Hou FYS, Hsu C-M, Winiarz JG, et al. Cytotoxicity in the age of nano: The role of fourth period transition metal oxide nanoparticle physicochemical properties. Chemico-Biological Interactions 2013; 206: 319-326. 
Das PP, Agarkar SA, Mukhopadhyay S, Manju U, Ogale SB, Devi PS. Defects in chemically synthesized and thermally processed $\mathrm{ZnO}$ nanorods: Implications for active layer properties in dye-sensitized solar cells. Inorganic Chemistry 2014; 53: 3961-3972.

Devan RS, Patil RA, Lin J-H, Ma Y-R. One-Dimensional Metal-Oxide Nanostructures: Recent Developments in Synthesis, Characterization, and Applications. Advanced Functional Materials 2012; 22: 33263370.

Djurisic $A B$, Leung YH, Ching Ng AM. Strategies for improving the efficiency of semiconductor metal oxide photocatalysis. Materials Horizons 2014; 1: 400-410.

Djurišić AB, Leung YH, Ng AMC, Xu XY, Lee PKH, Degger N, et al. Toxicity of metal oxide nanoparticles: Mechanisms, characterization, and avoiding experimental artefacts. Small 2015; 11: 26-44.

Faisal M, Ismail AA, Ibrahim AA, Bouzid H, Al-Sayari SA. Highly efficient photocatalyst based on Ce doped ZnO nanorods: Controllable synthesis and enhanced photocatalytic activity. Chemical Engineering Journal 2013; 229: 225-233.

Fecht HJ. Nanostructure formation by mechanical attrition. Nanostructured Materials 1995; 6: 33-42.

Gajewicz A, Schaeublin N, Rasulev B, Hussain S, Leszczynska D, Puzyn T, et al. Towards understanding mechanisms governing cytotoxicity of metal oxides nanoparticles: Hints from nano-QSAR studies. Nanotoxicology 2015; 0: 1-13.

Garcia G, Buonsanti R, Runnerstrom EL, Mendelsberg RJ, Llordes A, Anders A, et al. Dynamically modulating the surface plasmon resonance of doped semiconductor nanocrystals. Nano Letters 2011; 11: 4415-4420.

George S, Lin S, Ji Z, Thomas CR, Li L, Mecklenburg M, et al. Surface defects on plate-shaped silver nanoparticles contribute to its hazard potential in a fish gill cell line and Zebrafish embryos. ACS Nano 2012; 6: 3745-3759.

Gilstrap RAJ. A colloidal nanoparticle form of indium tin oxide: System development and characterization. Material Science and Engineering. PhD. Georgia Institute of Technology, Atlanta, GA, 2009.

Goings JJ, Schimpf AM, May JW, Johns RW, Gamelin DR, Li X. Theoretical Characterization of ConductionBand Electrons in Photodoped and Aluminum-Doped Zinc Oxide (AZO) Quantum Dots. The Journal of Physical Chemistry C 2014; 118: 26584-26590.

Guo MY, Ng AMC, Liu F, Djurišić AB, Chan WK, Su H, et al. Effect of native defects on photocatalytic properties of ZnO. The Journal of Physical Chemistry C 2011; 115: 11095-11101.

Guo Y, Zhang X-w, Weng W-H, Han G-r. Structure and properties of nitrogen-doped titanium dioxide thin films grown by atmospheric pressure chemical vapor deposition. Thin Solid Films 2007; 515: 7117-7121.

Hoque A, Boruah R, Das SK. Tunable optical properties of $\mathrm{ZnO}$ via doping monovalent $\left(\mathrm{Li}^{+}\right)$, divalent $\left(\mathrm{Mn}^{2+}\right)$ and trivalent $\left(\mathrm{Fe}^{3+}\right)$ cations. Materials Chemistry and Physics 2014; 147: 213-217.

Ischenko V, Polarz S, Grote D, Stavarache V, Fink K, Driess M. Zinc Oxide Nanoparticles with Defects. Advanced Functional Materials 2005; 15: 1945-1954.

Janotti A, Van de Walle CG. New insights into the role of native point defects in ZnO. Journal of Crystal Growth 2006; 287: 58-65.

Janotti A, Van de Walle CG. Native point defects in ZnO. Physical Review B 2007; 76: 165202.

Jitti-a-Porn P, Suwanhoon S, Amornpitoksuk P, Patarapaiboolchai O. Defects and the optical band gap of ZnO nanoparticles prepared by a grinding method. Journal of Ceramic Processing Research 2011; 12: 85-89.

Ju-Nam Y, Lead JR. Manufactured nanoparticles: An overview of their chemistry, interactions and potential environmental implications. Science of The Total Environment 2008; 400: 396-414.

Kaweeteerawat C, Ivask A, Liu R, Zhang H, Chang CH, Low-Kam C, et al. Toxicity of metal oxide nanoparticles in Escherichia coli correlates with conduction band and hydration energies. Environmental Science \& Technology 2015; 49: 1105-1112. 
419

420

421

422

423

424

425

426

427

428

429

430

431

432

433

434

435

436

437

438

439

440

441

442

443

444

445

446

447

448

449

450

451

452

453

454

455

456

457

458

459

460

461

462

463

464

465

466

Khan MM, Ansari SA, Pradhan D, Ansari MO, Han DH, Lee J, et al. Band gap engineered $\mathrm{TiO}_{2}$ nanoparticles for visible light induced photoelectrochemical and photocatalytic studies. Journal of Materials Chemistry A 2014a; 2: 637-644.

Khan MM, Ansari SA, Pradhan D, Han DH, Lee J, Cho MH. Defect-induced band gap narrowed $\mathrm{CeO}_{2}$ nanostructures for visible light activities. Industrial \& Engineering Chemistry Research 2014b; 53: 9754-9763.

Klaine SJ, Alvarez PJJ, Batley GE, Fernandes TF, Handy RD, Lyon DY, et al. Nanomaterials in the environment: Behavior, fate, bioavailability, and effects. Environmental Toxicology \& Chemistry 2008; 27: 1825-1851.

Kumar A, Pandey AK, Singh SS, Shanker R, Dhawan A. Engineered $\mathrm{ZnO}$ and $\mathrm{TiO}_{2}$ nanoparticles induce oxidative stress and DNA damage leading to reduced viability of Escherichia coli. Free Radical Biology and Medicine 2011; 51: 1872-1881.

Kumar SG, Rao KSRK. Zinc oxide based photocatalysis: tailoring surface-bulk structure and related interfacial charge carrier dynamics for better environmental applications. RSC Advances 2015; 5: 3306-3351.

Laks D, Van de Walle C, Neumark G, Pantelides S. Role of native defects in wide-band-gap semiconductors. Physical review letters 1991; 66: 648.

Lakshmi Prasanna V, Vijayaraghavan R. Insight into the Mechanism of Antibacterial Activity of ZnO: Surface Defects Mediated Reactive Oxygen Species Even in the Dark. Langmuir 2015; 31: 91559162.

Lawrence NJ, Brewer JR, Wang L, Wu T-S, Wells-Kingsbury J, Ihrig MM, et al. Defect engineering in cubic cerium oxide nanostructures for catalytic oxidation. Nano Letters 2011; 11: 2666-2671.

Leach AM, McDowell M, Gall K. Deformation of Top-Down and Bottom-Up Silver Nanowires. Advanced Functional Materials 2007; 17: 43-53.

Li Y, Niu J, Zhang W, Zhang L, Shang E. Influence of aqueous media on the ROS-mediated toxicity of ZnO nanoparticles toward green fluorescent protein-expressing Escherichia coli under UV-365 irradiation. Langmuir 2014; 30: 2852-2862.

Li Y, Zhang W, Niu J, Chen Y. Mechanism of Photogenerated Reactive Oxygen Species and Correlation with the Antibacterial Properties of Engineered Metal-Oxide Nanoparticles. ACS Nano 2012; 6: 5164-5173.

Lison D, Laloy J, Corazzari I, Muller J, Rabolli V, Panin N, et al. Sintered indium-tin-oxide (ITO) particles: A new pneumotoxic entity. Toxicological Sciences 2009; 108: 472-481.

Liu X, Wu X, Cao H, Chang RPH. Growth mechanism and properties of ZnO nanorods synthesized by plasma-enhanced chemical vapor deposition. Journal of Applied Physics 2004; 95: 3141-3147.

Lounis SD, Runnerstrom EL, Bergerud A, Nordlund D, Milliron DJ. Influence of Dopant Distribution on the Plasmonic Properties of Indium Tin Oxide Nanocrystals. Journal of the American Chemical Society 2014a; 136: 7110-7116.

Lounis SD, Runnerstrom EL, Llordés A, Milliron DJ. Defect chemistry and plasmon physics of colloidal metal oxide nanocrystals. The Journal of Physical Chemistry Letters 2014b; 5: 1564-1574.

McCluskey MD, Jokela SJ. Defects in ZnO. Journal of Applied Physics 2009; 106: 1-13.

Merz TA, Doutt DR, Bolton T, Dong Y, Brillson LJ. Nanostructure growth-induced defect formation and band bending at ZnO surfaces. Surface Science 2011; 605: L20-L23.

Murphy CJ, Sau TK, Gole AM, Orendorff CJ, Gao J, Gou L, et al. Anisotropic metal nanoparticles: synthesis, assembly, and optical applications. The Journal of Physical Chemistry B 2005; 109: 13857-13870.

Myneni SCB, Brown JT, Martinez GA, Meyer-Ilse W. Imaging of Humic Substance Macromolecular Structures in Water and Soils. Science 1999; 286: 1335-1337.

Nel A, Xia T, Mädler L, Li N. Toxic potential of materials at the nanolevel. Science 2006; 311: 622-627.

Norris DJ, Efros AL, Erwin SC. Doped nanocrystals. Science 2008; 319: 1776-1779. 
467

468

469

470

471

472

473

474

475

476

477

478

479

480

481

482

483

484

485

486

487

488

489

490

491

492

493

494

495

496

497

498

499

500

501

502

503

504

505

506

507

508

509

510

511

512

513

514

Otero-González L, García-Saucedo C, Field JA, Sierra-Álvarez R. Toxicity of $\mathrm{TiO}_{2}, \mathrm{ZrO}_{2}, \mathrm{Fe}^{0}, \mathrm{Fe}_{2} \mathrm{O}_{3}$, and $\mathrm{Mn}_{2} \mathrm{O}_{3}$ nanoparticles to the yeast, Saccharomyces cerevisiae. Chemosphere 2013; 93: 1201-1206.

Pacurari M, Qian Y, Fu W, Schwegler-Berry D, Ding M, Castranova V, et al. Cell permeability, migration, and reactive oxygen species induced by multiwalled carbon nanotubes in human microvascular endothelial cells. Journal of Toxicology and Environmental Health, Part A 2011; 75: 112-128.

Pan X, Yang M-Q, Fu X, Zhang N, Xu Y-J. Defective TiO2 with oxygen vacancies: synthesis, properties and photocatalytic applications. Nanoscale 2013; 5: 3601-3614.

Park E-J, Choi J, Park Y-K, Park K. Oxidative stress induced by cerium oxide nanoparticles in cultured BEAS2B cells. Toxicology 2008; 245: 90-100.

Pelaez M, Nolan NT, Pillai SC, Seery MK, Falaras P, Kontos AG, et al. A review on the visible light active titanium dioxide photocatalysts for environmental applications. Applied Catalysis B: Environmental 2012; 125: 331-349.

Polarz S, Roy A, Merz M, Halm S, Schröder D, Schneider L, et al. Chemical Vapor Synthesis of Size-Selected Zinc Oxide Nanoparticles. Small 2005; 1: 540-552.

Rehman S, Ullah R, Butt AM, Gohar ND. Strategies of making TiO2 and ZnO visible light active. Journal of Hazardous Materials 2009; 170: 560-569.

Röhder LA, Brandt T, Sigg L, Behra R. Influence of agglomeration of cerium oxide nanoparticles and speciation of cerium(III) on short term effects to the green algae Chlamydomonas reinhardtii. Aquatic Toxicology 2014; 152: 121-130.

Rossi T, Penfold TJ, Rittmann-Frank MH, Reinhard M, Rittmann J, Borca CN, et al. Characterizing the Structure and Defect Concentration of ZnO Nanoparticles in a Colloidal Solution. The Journal of Physical Chemistry C 2014; 118: 19422-19430.

Saleh NB, Afrooz A, Bisesi Jr JH, Aich N, Plazas-Tuttle J, Sabo-Attwood T. Emergent properties and toxicological considerations for nanohybrid materials in aquatic systems. Nanomaterials 2014; 4: 372-407.

Saleh NB, Aich N, Lead J, Plazas-Tuttle J, Lowry GV. Research strategy to determine when novel nanohybrids pose unique environmental risks. Environmental Science: Nano 2015; 2: 11-18 (Cover Article).

Sarkar A, Ghosh M, Sil PC. Nanotoxicity: Oxidative stress mediated toxicity of metal and metal oxide nanoparticles. Journal of Nanoscience and Nanotechnology 2014; 14: 730-743.

Sauer G, Brehm G, Schneider S, Nielsch K, Wehrspohn RB, Choi J, et al. Highly ordered monocrystalline silver nanowire arrays. Journal of Applied Physics 2002; 91: 3243.

Schimpf AM, Lounis SD, Runnerstrom EL, Milliron DJ, Gamelin DR. Redox Chemistries and Plasmon Energies of Photodoped $\ln _{2} \mathrm{O}_{3}$ and $\mathrm{Sn}$-Doped $\ln _{2} \mathrm{O}_{3}$ (ITO) Nanocrystals. J. Am. Chem. Soc. (Accepted) 2014a.

Schimpf AM, Lounis SD, Runnerstrom EL, Milliron DJ, Gamelin DR. Redox Chemistries and Plasmon Energies of Photodoped In2O3 and Sn-Doped In2O3 (ITO) Nanocrystals. Journal of the American Chemical Society 2014b.

Schimpf AM, Ochsenbein ST, Buonsanti R, Milliron DJ, Gamelin DR. Comparison of Extra Electrons in Colloidal n-Type Al3+-Doped and Photochemically Reduced ZnO Nanocrystals. Chemical Communications 2012.

Schmidt-Mende L, MacManus-Driscoll JL. ZnO - nanostructures, defects, and devices. Materials Today 2007; 10: 40-48.

Sekiguchi T, Miyashita S, Obara K, Shishido T, Sakagami N. Hydrothermal growth of ZnO single crystals and their optical characterization. Journal of Crystal Growth 2000; 214-215: 72-76.

Sharma V, Anderson D, Dhawan A. Zinc oxide nanoparticles induce oxidative DNA damage and ROStriggered mitochondria mediated apoptosis in human liver cells (HepG2). Apoptosis 2012; 17: 852-870. 
515

516

517

518

519

520

521

522

523

524

525

526

527

528

529

530

531

532

533

534

535

536

537

538

539

540

541

542

543

544

545

546

547

548

549

550

551

552

553

554

555

556

557

558

559

560

561

Song W, Zhang J, Guo J, Zhang J, Ding F, Li L, et al. Role of the dissolved zinc ion and reactive oxygen species in cytotoxicity of ZnO nanoparticles. Toxicology Letters 2010; 199: 389-397.

Tam KH, Cheung CK, Leung YH, Djurišić AB, Ling CC, Beling CD, et al. Defects in ZnO Nanorods Prepared by a Hydrothermal Method. The Journal of Physical Chemistry B 2006; 110: 20865-20871.

von Moos N, Slaveykova VI. Oxidative stress induced by inorganic nanoparticles in bacteria and aquatic microalgae - state of the art and knowledge gaps. Nanotoxicology 2014; 8: 605-630.

Wang H, Jia L, Bogdanoff P, Fiechter S, Mohwald H, Shchukin D. Size-related native defect engineering in high intensity ultrasonication of nanoparticles for photoelectrochemical water splitting. Energy \& Environmental Science 2013; 6: 799-804.

Wang J, Wang Z, Huang B, Ma Y, Liu Y, Qin X, et al. Oxygen vacancy induced band-gap narrowing and enhanced visible light photocatalytic activity of ZnO. ACS Applied Materials \& Interfaces 2012a; 4: 4024-4030.

Wang N, Cai Y, Zhang RQ. Growth of nanowires. Materials Science and Engineering: R: Reports 2008; 60: $1-51$.

Wang Z, Li N, Zhao J, White JC, Qu P, Xing B. CuO nanoparticle interaction with human epithelial cells: Cellular uptake, location, export, and genotoxicity. Chemical Research in Toxicology 2012b; 25: 1512-1521.

Wang Z, Zu X, Zhu S, Wang L. Green luminescence originates from surface defects in ZnO nanoparticles. Physica E: Low-dimensional Systems and Nanostructures 2006; 35: 199-202.

Ward MR, Boyes ED, Gai PL. Aberration Corrected (S)TEM and Nano Beam Diffraction (NBD) of Pt and Pd on Al 203 Catalysts. Journal of Physics: Conference Series 2014; 522: 012068.

Warwick T, Franck K, Kortright J, Meigs G, Moronne M, Myneni S, et al. A scanning transmission x-ray microscope for materials science spectromicroscopy at the advanced light source. Review of scientific instruments 1998; 69: 2964-2973.

Waychunas GA, Zhang H. Structure, Chemistry, and Properties of Mineral Nanoparticles. Elements 2008; 4: 381-387.

Xing YJ, Xi ZH, Xue ZQ, Zhang XD, Song JH, Wang RM, et al. Optical properties of the ZnO nanotubes synthesized via vapor phase growth. Applied Physics Letters 2003; 83: 1689.

Xue X-D, Wang T, Jiang J, Wu Y-C. Hydrogen- and corrosion-induced defect characterization of ZnO single crystal: A slow positron beam study. physica status solidi (a) 2013; 210: 1418-1423.

Yang X, Gondikas AP, Marinakos SM, Auffan M, Liu J, Hsu-Kim H, et al. Mechanism of silver nanoparticle toxicity Is dependent on dissolved silver and surface coating in Caenorhabditis elegans. Environmental Science \& Technology 2011; 46: 1119-1127.

Yin $\mathrm{H}$, Casey PS. Effects of iron or manganese doping of $\mathrm{ZnO}$ nanoparticles on their dissolution, ROS generation and cytotoxicity. RSC Advances 2014; 4: 26149-26157.

Zhang C, Lin J. Defect-related luminescent materials: synthesis, emission properties and applications. Chemical Society Reviews 2012; 41: 7938-7961.

Zhang H, Ji Z, Xia T, Meng H, Low-Kam C, Liu R, et al. Use of metal oxide nanoparticle band gap to develop a predictive paradigm for oxidative stress and acute pulmonary inflammation. ACS Nano 2012; 6: 4349-4368.

Zhang L, Jiang Y, Ding Y, Daskalakis N, Jeuken L, Povey M, et al. Mechanistic investigation into antibacterial behaviour of suspensions of $\mathrm{ZnO}$ nanoparticles against $E$. coli. Journal of Nanoparticle Research 2010; 12: 1625-1636.

Zhang X, Qin J, Xue Y, Yu P, Zhang B, Wang L, et al. Effect of aspect ratio and surface defects on the photocatalytic activity of ZnO nanorods. Sci. Rep. 2014; 4.

Zhang Z, Fenter P, Cheng L, Sturchio NC, Bedzyk MJ, Předota M, et al. Ion Adsorption at the Rutile-Water Interface: Linking Molecular and Macroscopic Properties. Langmuir 2004; 20: 4954-4969. 
Table 1. Conflicting toxicity mechanisms of reported for metal oxide nanoparticles.

\begin{tabular}{|c|c|c|}
\hline Particle & ROS Mediation & Non-ROS Mediation \\
\hline $\mathrm{Ag}$ & $\begin{array}{l}\text { Key mechanism: ROS resulted in apoptosis to } \\
\text { eukaryotic cells. } \\
\text { Particle sources: Sigma Aldrich using polyol } \\
\text { reduction of silver salts (Catalog \# 576832, St. } \\
\text { Louis, MO, USA) (Chairuangkitti et al., 2013) } \\
\text { and Air Force Research Laboratory (Brooks } \\
\text { AFB, TX, USA) (Hussain et al., 2005). }\end{array}$ & $\begin{array}{l}\text { Key Mechanism: Dissolution } \\
\text { Particle sources: In-house synthesis with } \\
\text { mercaptosuccinic acid capping by sodium } \\
\text { borohyride mediated reduction of silver } \\
\text { nitrate (Chambers et al., 2014), citrate (by } \\
\text { sodium citrate mediated reduction of sodium } \\
\text { nitrate) and gum Arabic coatings (by sodium } \\
\text { borohyride mediated reduction of silver }\end{array}$ \\
\hline
\end{tabular}




\begin{tabular}{|c|c|c|}
\hline & & $\begin{array}{l}\text { nitrate) (Yang et al., 2011); NanoAmor } \\
\text { (Houston, TX, USA) commercial source } \\
\text { with polyvinyl pyrrolidone (PVP) coating } \\
\text { (Yang et al., 2011). }\end{array}$ \\
\hline $\mathrm{ZnO}$ & $\begin{array}{l}\text { Key mechanism: ROS-mediated bacterial } \\
\text { inactivation and cytotoxicity. } \\
\text { Particle sources: In-house synthesis by flame } \\
\text { spray pyrolysis (Kaweeteerawat et al., 2015); } \\
\text { Sigma Chemical Co. Ltd or Sigma Aldrich Co. } \\
\text { LLC (Kumar et al., 2011; Li et al., 2014; } \\
\text { Sharma et al., 2012). }\end{array}$ & $\begin{array}{l}\text { Key mechanism: Dissolved ion toxicity to } \\
\text { bacteria, zebrafish, and human cells. } \\
\text { Particle sources: In-house synthesis by } \\
\text { flame spray pyrolysis (Zhang et al., 2012); } \\
\text { IBU-tec Advanced Materials AG (Weimar, } \\
\text { Germany) (Buerki-Thurnherr et al., 2013); } \\
\text { Nanostructured and Amorphous Materials, } \\
\text { (Los Alamos, NM, USA) (Chusei et al., } \\
\text { 2013). }\end{array}$ \\
\hline $\mathrm{CuO}$ & $\begin{array}{l}\text { Key mechanism: ROS-mediated toxicity to } \\
\text { bacteria and human cell lines. } \\
\text { Particle sources: In-house synthesis by flame } \\
\text { spray pyrolysis (Kaweeteerawat et al., 2015); } \\
\text { Beijing Nanchen S\&T Ltd., Beijing, China } \\
\text { (Wang et al., 2012b). }\end{array}$ & $\begin{array}{l}\text { Key mechanism: Dissolution-mediated } \\
\text { cytotoxicity to human cell lines. } \\
\text { Particle sources: In-house synthesis by } \\
\text { flame spray pyrolysis } \\
\text { (Zhang et al., 2012); Nanostructured and } \\
\text { Amorphous Materials (Los Alamos, NM, } \\
\text { USA) (Chusuei et al., 2013). }\end{array}$ \\
\hline $\mathrm{CeO}_{2}$ & $\begin{array}{l}\text { Key mechanism: Cytotoxicity to human } \\
\text { bronchial epithelial cells (BEAS-2B) from } \\
\text { ROS. } \\
\text { Particle source: In-house supercritical } \\
\text { synthesis (Park et al., 2008). }\end{array}$ & $\begin{array}{l}\text { Key mechanism: Dissolution based toxicity } \\
\text { to aquatic organism. } \\
\text { Particle source: Commercial Nanograde, } \\
\text { Staefa, Switzerland (Röhder et al., 2014). }\end{array}$ \\
\hline $\mathrm{Mn}_{2} \mathrm{O}_{3}$ & $\begin{array}{l}\text { Key mechanism: ROS-mediated toxicity to } \\
\text { bacteria, yeast, and human cell lines. } \\
\text { Particle sources: In-house synthesis by flame } \\
\text { spray pyrolysis (Kaweeteerawat et al., 2015; } \\
\text { Zhang et al., 2012); Sky-Spring Nanomaterials, } \\
\text { (Houston, TX, USA (Otero-González et al., } \\
\text { 2013). }\end{array}$ & $\begin{array}{l}\text { Key mechanism: Dissolution-mediated } \\
\text { cytotoxicity. } \\
\text { Particle source: Nanostructured and } \\
\text { Amorphous Materials (Los Alamos, NM, } \\
\text { USA) (Chusuei et al., 2013). }\end{array}$ \\
\hline
\end{tabular}




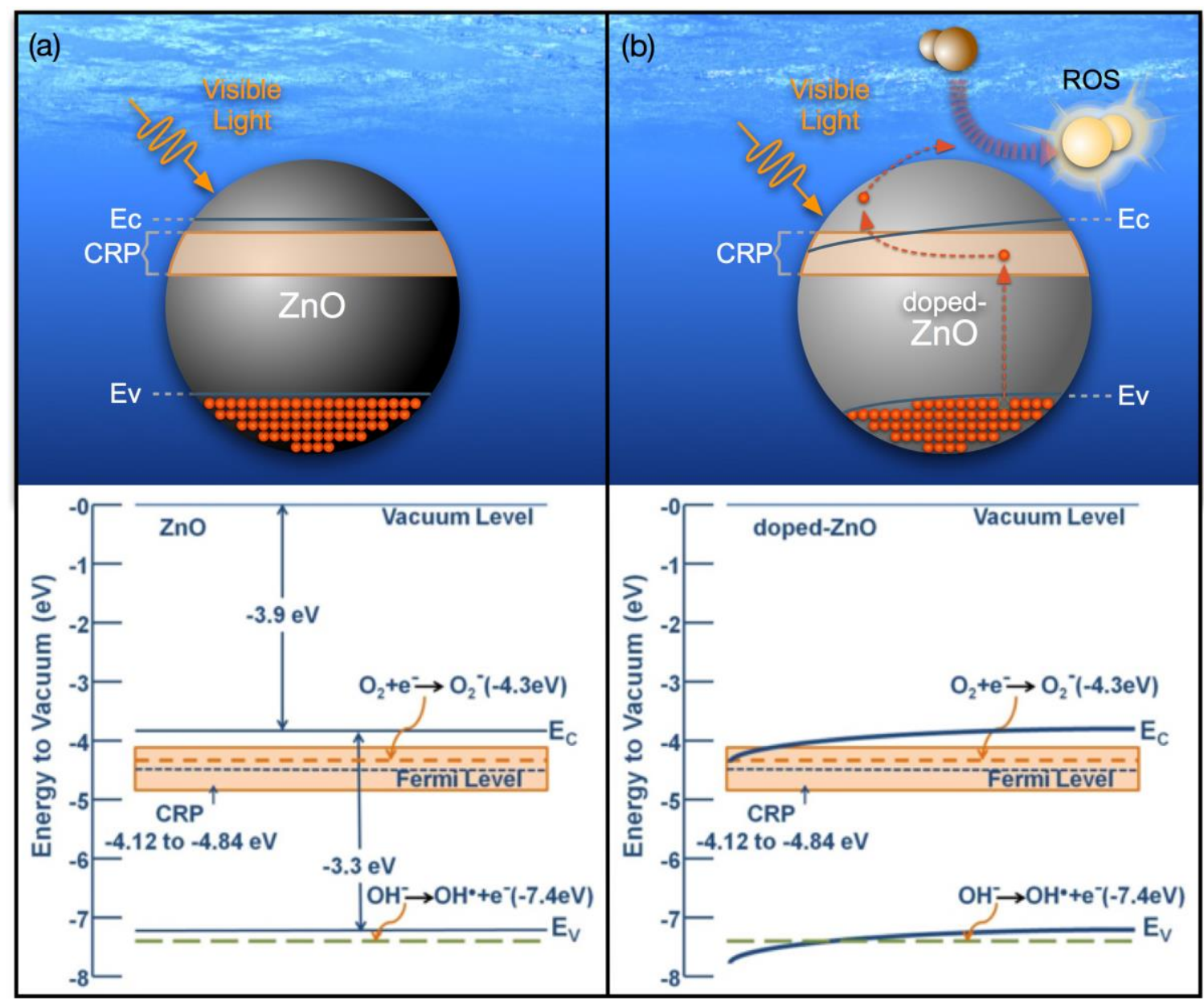

603 Fig. 1. (a) un-doped $\mathrm{ZnO}$ nanoparticle and its band structure showing electrical conduction band $604\left(\mathrm{E}_{\mathrm{c}}\right)$ distant from cellular redox potential (CRP). (b) ROS active doped-ZnO nanoparticle and its $605 \mathrm{E}_{\mathrm{c}}$ re-positioning within CRP via doping-induced band bending. 


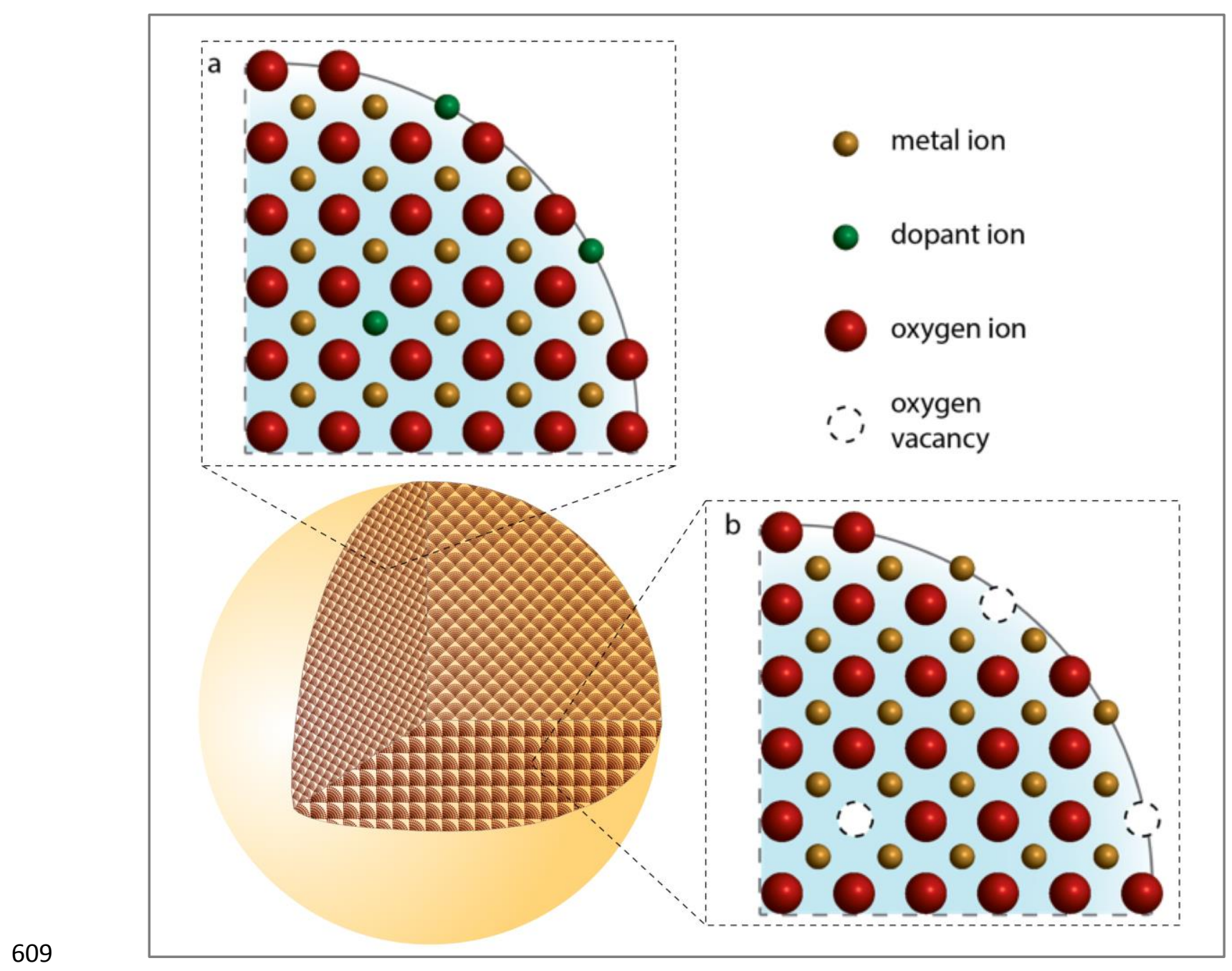

Fig. 2. Distribution of (a) dopant ions and (b) defects or vacancies in a crystal structure. 